\title{
Síndrome da hipermobilidade articular em jovem
}

\author{
Joint hypermobility syndrome in a young man
}

\author{
Joana Neves ${ }^{1}$, Inês Cunha ${ }^{2}$, Renata Aguiar ${ }^{3}$, Anabela Barcelos ${ }^{4}$ \\ ${ }^{1}$ Interna de Formação Específica de Medicina Interna do Serviço de Medicina Interna do Centro Hospitalar do Baixo Vouga, Aveiro. \\ ${ }^{2}$ Assistente Hospitalar de Reumatologia do Serviço de Reumatologia do Centro Hospitalar do Baixo Vouga, Aveiro. \\ ${ }^{3}$ Interna de Formação Específica de Reumatologia do Serviço de Reumatologia do Centro Hospitalar do Baixo Vouga, Aveiro. \\ ${ }^{4}$ Assistente Hospitalar Graduada de Reumatologia do Serviço de Reumatologia do Centro Hospitalar do Baixo Vouga, Aveiro.
}

\begin{abstract}
Joint hypermobility syndrome (JHS) is a hereditary connective tissue disorder characterized by symptomatic generalized joint hypermobility. Other features such as luxations and subluxations, periarticular lesions and cutaneous or other organ manifestations due to collagen defects are included in JHS clinical criteria. JHS may be clinically indistinct from Ehlers-Danlos syndrome hypermobility type (EDS).

We report the case of a 14 year old male patient, with chronic low back pain and generalized joint hypermobility. He also presented a marfanoid habitus, hand joint alterations and striae in the right dorsal region. He fulfilled the Brighton Criteria therefore, after excluding other connective tissue diseases, the diagnosis of JHS was established.

JHS is an underestimated and underdiagnosed disease, and must be contemplated in front of musculoskeletal pain associated with generalized hypermobility. The authors describe this case highlighting the importance of looking for signs and symptoms which allow the earlier diagnosis and management.
\end{abstract}

Keywords: connective tissue disorder, joint hypermobility, low back pain, striae, young man.

Palabras clave: trastorno del tejido conectivo, hipermovilidad articular, lumbago, estrías cutáneas.

\section{Introduction}

Joint hypermobility syndrome (JHS) is a hereditary connective tissue disorder included in the group of hypermobility syndromes, and is characterized by symptomatic generalized joint hypermobility (GJH) ${ }^{1}$. Previously JHS was recognized as benign joint hypermobility syndrome, but because of their character not so benign nowadays is recognized just as JHS 2 . JHS is manifested in childhood and eventually throughout adult life, often affecting the quality of life ${ }^{2}$. It has long been undervalued and therefore underdiagnosed, so its prevalence is not known exactly ${ }^{3}$. This entity has an hereditary component, with an autosomal dominant pattern, some authors stating that about $50 \%$ of patients will have one first degree relative with the same syndrome ${ }^{1}$.

The diagnosis of JHS is based on clinical history and physical examination, and should always be considered in the context of symptomatic GJH. The Beighton score is used to identify GJH ${ }^{4}$ (Table I) and the Brighton criteria (Table II) helps differentiating JHS of other hypermobility syndromes ${ }^{5}$.

Chronic pain is the most frequent complaint in JHS and can affect joints, muscles or ligaments. In adolescents and adults, low back pain is the most common complaint ${ }^{3}$. Other frequent complains reflecting collagen defects are joint luxations/subluxations, skin hyperlaxity, stretch marks and thin skin, ptosis and myopia 4 . These patients may also present symptoms related to dysautonomia, as postural hypotension and palpitations, and even pre-syncope and syncope may occur $^{6}$. Repeated urinary infections and bedwetting, as gastroesophageal reflux and constipation, also appear to partner with autonomic dysfunction ${ }^{6}$.

\section{Clinical report}

The authors present the case of a 14 year old man who was admitted as an inpatient to the pediatric ward for back pain. The patient had a three month history of low back pain of moderate intensity with exacerbation periods, so far interpreted as growing pains. The pain had a non-defined pattern, waking the patient at night and worsening after physical activity, making it impossible to perform more intense and prolonged efforts. Had poor response to analgesics and non-steroid anti-inflammatory drugs (NSAIDs). The patient denied other musculoskeletal complaints and mentioned frequent "palpitations", for which he was treated with bisoprolol $2.5 \mathrm{mg} /$ day. He denied other complaints suggesting other organ involvement. He also reported anxiety, panic attacks and learning disability, confirmed by his mother. He had no other relevant medical history. On general physical examination, the patient had lanky biotype, marfanoid habitus (arm span to total height ratio 1.05 (positive when $>1.03$ ) and upper segment to lower segment ratio 0.80 (positive when $<0.89$ )), mild arachnodactyly (with positive Steinberg's thumb sign and wrist sign) structural scoliosis with positive Adams test, dorsal kyphosis, lumbar hyperlordosis (Figure 1) and striae on the right dorsal region (Figure 2), without hyperextensible skin. He had active hyperextension of the elbow (20 bilaterally) (Figure 1) and proximal interphalangeal joints and hyperflexion of distal interphalangeal joints (Figure 3). He met GJH criteria, according to the Beighton score (total score of 7 in 9 points - apposition of thumb to flexor aspect of forearm bilateraly, dorsiflexion of fifth metacarpophalangeal joint $>90^{\circ}$ bilateraly, hyperextension of the elbow $>10^{\circ}$ bilateraly and placing flat hands on the floor with straight legs) (Table I). He did not have arthritis or periarticular lesions. There were no suggestive signs of other connective tissue diseases. The patient met the Brighton criteria for JHS (Beighton score $\geq 4 / 9$, back pain during plus than 3 month, Marfanoid habitus and dorsal unilateral striae) (Table II). The laboratory workup revealed no abnormalities, namely normal inflammatory 
parameters. Radiograph of the lumbar spine confirmed dorsolumbar scoliosis, dorsal kyphosis and lumbar hyperlordosis, with no limb dysmetria. The electrocardiogram demonstrated frequent supraventricular extrasystoles. The echocardiogram excluded mitral valve prolapse or thoracic aortic aneurysm. When discharged the patient and family were informed about the benign nature of this syndrome and he was referred to a physiatry appointment, where a muscular enhancement plan was developed.

\section{Discussion}

The diagnosis of JHS is based on clinical criteria - the Brighton Criteria. There are no diagnostic test for this syndrome, so, to diagnose correctly JHS, careful clinical examination and exclusion of others heritable disorders of connective tissue is required, as Ehlers-Danlos syndrome (EDS) vascular type, Marfan syndrome, Loeys-Dietz syndrome and Aneurysm-Osteoarthritis syndrome, which can cause serious complications, as arterial or organ rupture, potentially fatal ${ }^{5,7}$. Echocardiography has therein an important role, since it is noninvasive exam that quickly detects changes in the aortic root (as aneurysm or aortic dissection) ${ }^{8}$.

This syndrome is often indistinguishable from EDS hypermobility type, being considered by many authors as the same entity ${ }^{3,9}$. Both are essentially manifested by GJH and skin changes, and there are no pathognomonic features. The Brighton criteria for JHS and Villefranche for EDS hypermobility type may allow the differentiation of the two syndromes, but that is often not possible?

The chronic pain is one of the symptoms with more impact to the life's patient, being the most limiting symptom ${ }^{2,10}$. In the past JHS was seen only as reaching the musculoskeletal system but nowadays it's faced as a multisystemic disorder that include chronic pain, autonomic dysfunction and gastrointestinal dysmotility ${ }^{11}$. Fatigue is the other most prevalent symptom but anxiety and depression are also frequent complaints, which are believed to be related to chronic pain, sometimes leading to panic attacks and learning difficulties ${ }^{10}$. There are no specific treatments for this syndrome. Pain management could be complex because it has multiple possible pathways like anxiety, muscular deconditioning, joint instability and central nervous system upregulation with generalized hyperalgesia ${ }^{12}$. The main purposes of treatment are symptomatic control and improvement of functional capacity. The patients should be taught to deal with the disease by modifying their activities, with self-care activities, preventing trauma by limiting the amplitude of movements, correcting posture and performing oriented physical exercise to muscle strengthening and joint stability, avoiding pain and articular wear ${ }^{1-3,8}$. These patients need to be managed for his JHS, as a multisystemic disease, and not for an individual symptom, as pain ${ }^{13}$. The use of analgesics and NSAIDs are generally ineffective and orthopedic surgery should be avoided ${ }^{10}$. Behavioral therapy is also recommended, particularly in patients with chronic pain, anxiety or panic attacks ${ }^{8,10}$.
Table I. Beighton score (range 0-9, each criterion scores 1 point for each side of the body, if present, with exception of placing flat hands on the floor; generalized hypermobility if total score $\geq 5$ ).

\begin{tabular}{|l|c|c|}
\hline & Esquerda & Direita \\
\hline Apposition of thumb to flexor aspect of forearm & 1 & 1 \\
\hline Dorsiflexion of fifth metacarpophalangeal joint $>90^{\circ}$ & 1 & 1 \\
\hline Hyperextension of the elbow $>10^{\circ}$ & 1 & 1 \\
\hline Hyperextension of the knee $>10^{\circ}$ & 1 & 1 \\
\hline Placing flat hands on the floor with straight legs & \multicolumn{2}{|c|}{1} \\
\hline
\end{tabular}

Table II. The revised Brighton 1998 criteria for Benign Joint Hypermobility Syndrome (BJHS): diagnose is made in the presence of either two major criteria, one major and two minor criteria, or four minor criteria. Two minor criteria will suffice where there is an unequivocally affected firstdegree relative.

\section{Major criteria}

1. A Beighton score $\geq 4 / 9$

2. Arthralgia for $>3$ months in four or more joints

\section{Minor criteria}

1. A Beighton score of $1-3 / 9$ ( $0-3$ if aged $\geq 50$ year)

2. Arthralgia ( $\geq 3$ month) in one to three joints, or back painzz ( $\geq 3$ month), or spondylosis, spondylolysis/spondylolisthesis

3. Dislocation/subluxation in more than one joint or in one joint on more than one occasion

4. Three or more soft tissue lesions (e.g. epicondylitis, tenosynovitis, bursitis)

5. Marfanoid habitus (tall, slim, arm span to total height ratio >1.03; upper segment to lower segment ratio $<0.89$, arachnodactily (+Steinberg/wrist signs))

6. Abnormal skin: striae or hyperextensibility, thin cutis, or papyraceous scarring

7. Eye signs: drooping eyelids or myopia, or antimongoloid slant

8. Varicose veins or hernia or uterine/rectal prolapse 
Figure 1. Lumbar hyperlordosis and hyperextention of the elbow

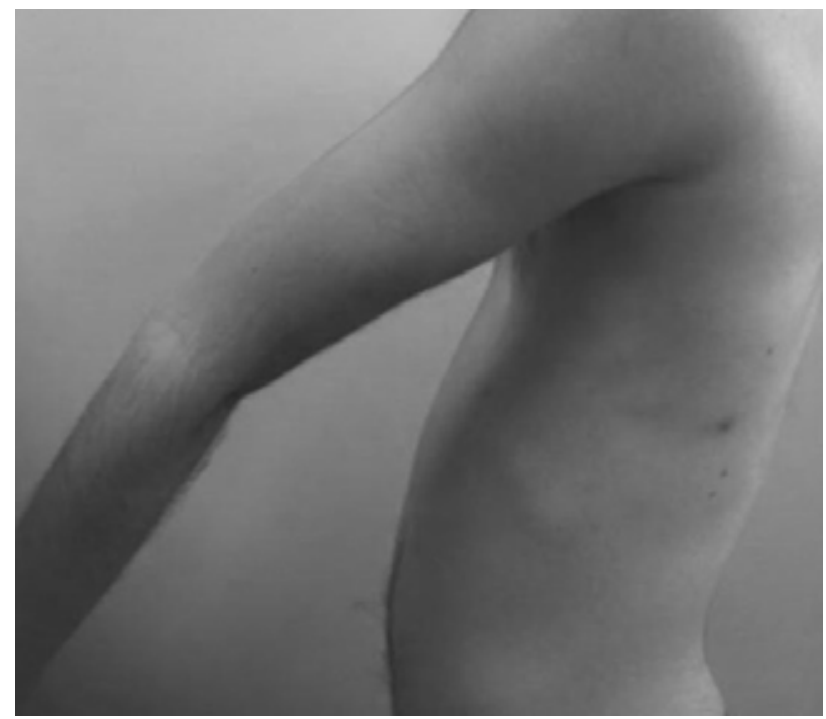

Figure 2. Striae on the right dorsal region.

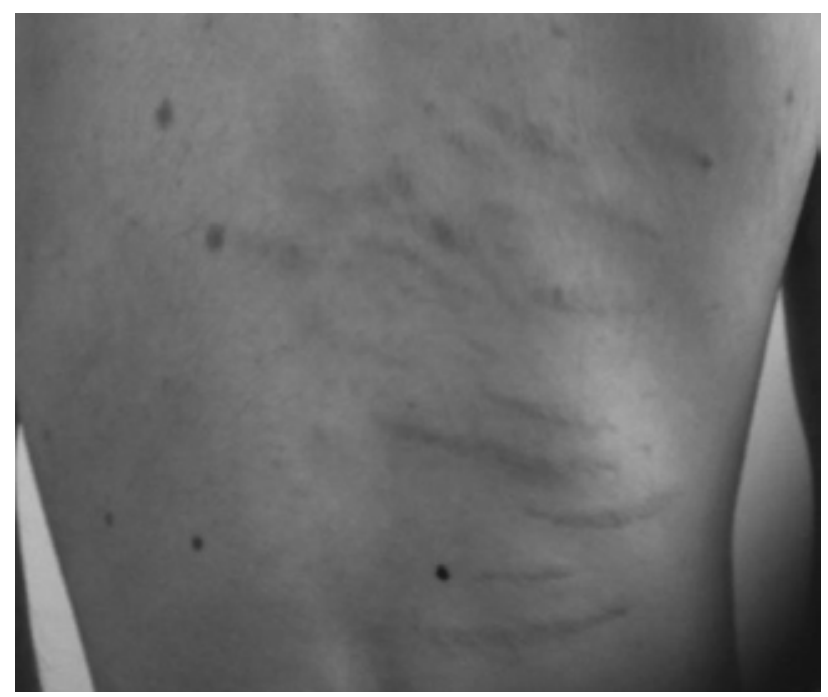

Figure 3. Hyperflexion of distal interphalangeal joints.

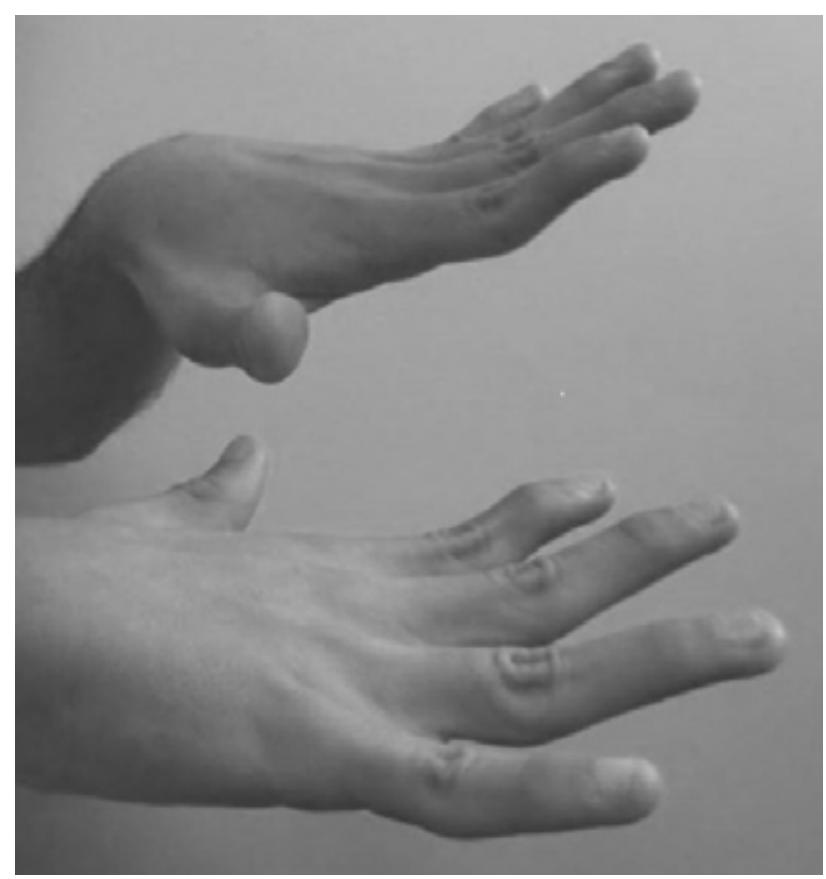

Our patient held a muscular enhancement plan, presenting now low back pain just when made efforts. He maintains follow up in physiatry and psychology appointments, with good outcomes and improvement in quality of life.

\section{Conclusion}

JHS is a frequent disease but that is underdiagnosed and undervalued. Although in most of the cases do not presents life-threatening complications affects the quality of life. If diagnosed early it can avoid unnecessary diagnostic investigation and family concern. Despite not have specific treatment some measures could be adopted to improve the quality of life of the child or adult, preventing cases of chronic pain and the limitations related.

\section{References}

1. Simpson MR. Benign Joint Hypermobility Syndrome: Evaluation, Diagnosis, and Management. J Am Osteopath Assoc 2006; 106: 531-536.

2. Ross J, Grahame R. Joint hypermobility syndrome. BMJ 2011; 342: 275-277.

3. Jacobs JW, da Silva JA. Hypermobility syndromes from the clinician's perspective: an overview. Acta Reumatol Port. 2014; 39(2):124-136.

4. Remvig L, Jensen DV, Ward RC. Epidemiology of general joint hypermobility and basis for the proposed criteria for benign joint hypermobility syndrome: review of the literature. J Rheumatol. 2007; 34(4): 804-9.

5. Grahame R, Bird HA, Child A. The revised (Brighton 1998) criteria for the diagnosis of benign joint hypermobility syndrome (BHJS). J Rheumatol 2000; 27: 1777-1779.

6. Gazit $Y$, Nahir AM, Grahame R, Jacob G. Dysautonomia in the joint hypermobility syndrome. Am J Med. 2003 Jul;115(1):33-40.

7. Pacey V, Tofts L, Wesley A, Collins F, Singh-Grewal D. Joint hypermobility syndrome:A review for clinicians. J Paediatr Child Health. 2015 Apr;51(4): 373-80. doi: 10.1111/ jpc. 12731.

8. Tofts LJ, Elliott EJ, Munns C, Pacey V, Sillence DO. The differential diagnosis of children with joint hypermobility: a review of the literature. Rheumatol Online J 2009 Jan. 5;7:1. doi: 10.1186/1546-0096-7-1.

9. Tinkle BT, Bird H, Grahame R, Lavallee M, Levy HP, Sillence D. The lack of clinical distinction between the hypermobility type of Ehlers-Danlos syndrome and the joint hypermobility syndrome (a.k.a. hypermobility syndrome). Am J Med Genet A 2009; 149A: 2368-2370.

10. Baeza-Velasco C, Gély-Nargeot MC, Bulbena Vilarrasa A, Bravo JF. Joint hypermobility syndrome: problems that require psychological intervention. Rheumatol Int. 2011 Sep;31(9):1131-6

11. Fikree A, Aziz Q, Grahame R.Joint hypermobility syndrome. Rheum Dis Clin North Am. 2013 May: 39(2): 419-430.

12. Scheper MC, de Vries JE, Verbunt J, Engelbert RH. Chronic pain in hypermobility syndrome and Ehlers-Danlos syndrome (hypermobility type): it is a challenge. J Pain Res. 2015 Aus 20; 8: 591-601.

13. Terry RH, Palmer ST, Rimes KA, Clark CJ, Simmonds JV, Horwood JP. Living with joint hypermobility syndrome: patient experiences of diagnosis, referral and self care. Fam Pract 2015 Jun; 32 (3): 354-8. 